иргизской воде на окисление, из-за бурного развития сине-зеленых водорослей и других простейших гидробионтов, что приводит к созданию анаэробной обстановки в придонном слое воды. Недоокисление органики достигает 3,5 ПДК [11]. Указанные прочессы привели к восстановлению ранее окисленных химических соединений, например марганца, в донных отложениях и переходу их в растворимые формы.

Степные реки типа Большого Иргиза в условиях Саратовского Заволжья в принципе непригодны для водоснабжения городов с населением более 40 тыс. чел. (г. Пугачёв), так как в реках недостаточно воды, а основной их сток приходится на весну. Река в процессе интенсивной хозяйственной деятельности на водосборе стала еще более маловодной. Строительство водохранилищ и прудов привело к резкому ухудшению качества воды в них из-за прекращения процессов самоочищения водных масс, заиления и эвтрофикации застойных водоемов, чего нельзя было предположить в 1950-е гг., когда до г. Пугачёва осуществлялась навигация с р. Волги.

Для сохранения ресурсов поверхностных вод в бассейне Большого Иргиза и в самом Иргизе необходимо:

- осуществить подпитку р. Большой Иргиз водой из р. Волги по Саратовскому оросительнообводнительному каналу;

- строго соблюдать экологические нормативы природопользования в водоохранных зонах (исключить попадание хозяйственных отходов в воды р. Большой Иргиз);

- периодически очищать русло реки и дно водохранилища от иловых накоплений;

- учитывая характер распределения соединений марганца в р. Большой Иргиз по вертикали, поднять уровень водозабора на 2,5-3 м;

- осуществить полную очистку резервуаров на очистных сооружениях (водоприемный колодец и резервуар для воды после хлорирования);
- в качестве реагентного метода деманганации воды применить озонирование, так как при высоких концентрациях растворенных форм марганца, находящегося в виде прочных комплексных соединений с органическими лигандами, перманганатометрический способ и деманганация хлорированием малоэффективны;

- утвердить областную целевую программу по оценке экологической обстановки на малых реках и их водосборах для разработки рекомендаций по рациональному природопользованию.

\section{Библиографический список}

1. Эколого-ресурсный атлас Саратовской области. Саратов, 1996.

2. Ресурсы поверхностных вод СССР. Т. 12. Нижнее Поволжье. Западный Казахстан. Вып. 1. Бассейн реки Волги ниже г. Чебоксары. М.; Л., 1971. 409 с.

3. Большая советская энциклопедия. 2-е изд. Т. 18. С. 437. 4. ГОСТ Р 51592-2000 «Вода. Общие требования к отбору проб». М., 2001. 30 c.

5. ГОСТ Р 51593-2000 «Вода питьевая. Отбор проб». M., $2001.6 \mathrm{c}$.

6. ГОСТ 17.1.5.01-80 «Охрана природы. Гидросфера. Общие требования к отбору проб донных отложений водных объектов для анализа на загрязненность». М., 1984. 9 с.

7. ГОСТ 4974-72 «Вода питьевая. Методы определения содержания марганца». М., 1976.7 с

8. ГОСТ 4011-72 «Вода питьевая. Методы измерения массовой концентрации общего железа». М., 1994. 9 с.

9. ГОСТ Р 52407-2005 «Вода питьевая. Методы определения жесткости». М., 2006. 4 с.

10. Гончарук Е.И. и др. Руководство к лабораторным занятиям по коммунальной гигиене: Учеб. пособие. M., 1990, $416 \mathrm{c}$.

11. Схема территориального планирования Пугачёвского района: В 4 т. Т. І. Общая характеристика района. Саратов, 2009. $214 \mathrm{c}$.

УДК [912.44:004] (470.44)

\title{
УЧЕБНО-КРАЕВЕДЧЕСКИЙ ЭЛЕКТРОННЫЙ АТЛАС САРАТОВСКОЙ ОБЛАСТИ: ПРИНЦИПЫ И МЕТОДЫ СОЗДАНИЯ
}

\section{Т.Д. Крысанова', Ю.В. Паршина, А.В. Федоров ${ }^{2}$, А.Н. Чумаченко ${ }^{1}$}

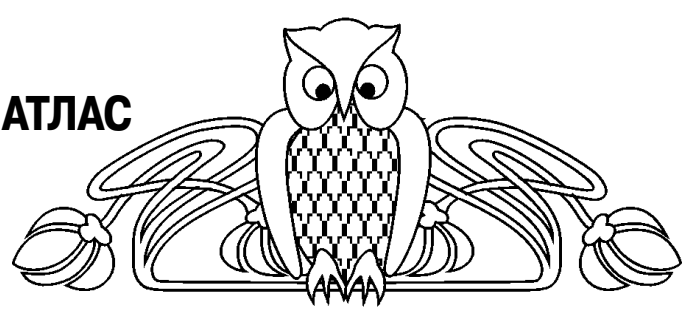

Саратовский государственный университет,

кафедра геоморфологии и геоэкологии

E-mail: geogr@sgu.ru

${ }_{1}^{1}$ кафедра физической географии и ландшафтной экологии

E-mail: Parshinajv@mail.ru

2 лаборатория геоинформации и тематического картографирования Научно-образовательного внедренческого центра геоинформационных технологий

E-mail: gis@sgu.ru
Развитие общества связано с накоплением территориальнораспределенной информации, где основную роль в накоплении и сохранении данных играют атласы, в том числе и электронные. В данной статье сформулированы методические принципы, на которых основываются разработка и создание учебных электронных атласов. В статье представлена последовательность этапов работы по проектированию и созданию учебно-краеведческого электронного атласа Саратовской области, а также раскрыты некоторые вопросы по методики его создания. 
Ключевые слова: электронный атлас, атласное картографирование, геоинформационное картографирование, учебнокраеведческий атлас.

\section{Educational-local History electronic Atlas of Saratov Region: Making foundations and Methods}

\section{T.D. Krysanova, J.V. Parshina, A.V. Fedorov,} A.N. Chumachenko

Society development is closely related to collecting of geographicallydistributed information, where the main accumulation and storage role plays atlases, and electronic atlases. The article represents work periods succession of projecting and making of Saratov region educational- local history electronic atlas. Also some aspects of atlas making methodology are disclosed.

Key words: electronic atlas, atlas mapping, geoinformatic mapping, educational-local history atlas.

Современное общество неразрывно связано с процессом информатизации. При этом одним из важнейших направлений данного процесса является использование информационных технологий в образовании. Эта тенденция соответствует изменившимся целям образования, которые требуют обновления методов, форм организации и средств обучения. Несомненно, это относится и к географическому образованию, для которого является исключительно важным применение на уроках, наряду с традиционными средствами, такими как атласы и контурные карты, новых и современных средств обучения, например электронных атласов.

На сегодняшний день подобные атласы приобретают все большую популярность, поскольку обеспечивают познавательную функцию географии на качественно новом техническом уровне. Еще одним немаловажным фактором, говорящим в пользу использования электронных атласов, является экономия трудовых, финансовых и временных затрат на создание, редактирование и обновление, в сравнение с их полиграфическими версиями

Реализация приоритетного национального проекта «Образование» и Программы регионализации школьного образования создала благоприятные условия для разработки пособий по географии Саратовской области с использованием современных технологий. В рамках инновационной образовательной программы «Формирование и реализация инновационных научных и образовательных программ подготовки и переподготовки конкурентоспособных специалистов в регионе на базе университетского комплекса» на основе научно-внедренческого образовательного центра геоинформационных технологий (НВОЦ «ГИСцентр» СГУ) (при географическом факультете) разработана концепция создания на базе геоинформационной системы Саратовской области учебно-методических материалов для высших и средних региональных учебных заведений. Среди таких материалов важное место отведено учебно- краеведческому электронному атласу Саратовской области.

При разработке структуры и содержания учебных атласов необходимо учитывать, что содержание образования по географии Саратовской области включает в себя изучение нескольких теоретических блоков, среди которых можно выделить географическое положение, историю освоения и заселения, хозяйственную оценку природных условий и ресурсов, типичные и уникальные природные комплексы, экологическую ситуацию и прогнозирование, охраняемые природные территории и объекты, население и трудовые ресурсы, национальный состав, традиции и обычаи народов, населяющих область, проблемы и перспективы развития региона и др.

Необходимо также учитывать, что изучение Саратовской области целесообразно проводить с широким использованием самостоятельных и практических работ учащихся по представленным темам.

В методическом плане содержание атласов должно отвечать требованиям, отражающим различные аспекты методики обучения географии. Каждое требование отражает определенное методическое содержание.

1. Планирование:

- соответствие иелям обучения - основополагающее условие создания учебных материалов. В соответствии с программой по географии целью обучения являются раскрытие географической картины мира, выработка научных взглядов на взаимосвязь природы и общества, раскрытие основ общественного производства, развитие географического мышления;

- соответствие содержанию учебных програми.

2. Контекст:

- раскрытие причинно-следственных связей изучаемых явлений, которое является специфическим принципом при составлении географических учебных материалов. В текстах и иллюстративных материалах необходимо учитывать и отражать взаимосвязь географических явлений, а также взаимосвязь и взаимозависимость явлений окружающего мира и деятельности человека;

- последовательная реализация методической кониепиии.

3. Фокусирование учебного процесса на деятельности учащихся:

- стимулирование мотивачии учашихся. Этот принцип представляет собой одно из основных дидактических требований к уроку - повышение интереса обучаемых к предмету.

- соответствие уровню предметных знаний, умений и навыков учашихся;

- соответствие познавательным интересам учашихся - требование подчеркивает концепции учебных материалов с точки зрения особенностей мотивационной сферы. 


\section{4. Доступность:}

- наглядный характер учебного материала. Требования к современному атласу предполагают включение в его разделы, материала сочетающего карты, космические снимки, диаграммы, рисунки, таблицы, тексты, справочный материал. Особое внимание уделяется использованию космических фотоизображений, которые должны органически войти в содержание атласов. Космические снимки способствуют раскрытию изучаемых понятий, более эффективному формированию представлений о тех или иных географических объектах или явлениях;

- оптимальное использование вербальноинформачионных и картографических материа лов. При составлении атласов должен соблюдаться следующий методический принцип: сопроводительная информация к наглядным материалам (картам, космическим снимкам, диаграммам, рисункам, таблицам, фотографиям, схемам и т.д.) должна способствовать более эффективному восприятию новых сведений по географии.

5. Самостоятельность:

- реализация принципов проблемно-ориентированного и поискового обучения. Данное требование носит инновационный характер и указывает на направление обучения от частного к общему, т.е. путем индукции. Ученики не получают готовых ответов, а самостоятельно, путем интенсивной мыслительной деятельности достигают необходимых результатов;

- ориентация на развитие мыслительных прочессов и продуктивного мышления обучаемых. Она предполагает создание условий, способствующих развитию продуктивного мышления учащихся, обучение их методам синтеза и анализа изучаемых явлений. Этот принцип тесно связан с вышеназванным требованием.

6. Формирование базовой компетенции:

- системы географических знаний. Данное требование является реализацией основной задачи обучения географии в школе - формирование системы географических знаний, в том числе и картографических;

- системы практических умений и навыков.

При разработке структуры и содержания региональных географических атласов, предназначенных для разных возрастных групп учащихся, нужно также учитывать основные тенденции географической науки, влияющие на содержание географического образования:

- интеграцию двух ветвей географии, усиление комплексных подходов. Это выразилось в объединении курсов физической и экономической географии, создании курсов, где общеземлеведческие знания тесно взаимосвязаны с комплексным страноведением. Это определяет необходимость включения в атласы комплексных карт как по региону в целом, так и отдельным его районам;

- экологизацию содержания географического образования требует рассмотрения ресурсовед- ческих вопросов, проблем сохранения живой и неживой природы, охраны окружающей среды, создания карт, раскрывающих экологические проблемы регионального и локального уровней;

- гуманизацию содержания географического образования, которая выражена в усилении внимания к человеческому, личностному фактору, социальным аспектам развития общества, что нашло отражение в изучении в большем объеме, чем ранее, историко-географических и страноведческих знаний. Следовательно, в атласы, желательно, включить карты по истории открытий и исследований территории, а также карты, отражающие языки, культуру, религиозные особенности населения региона;

- практическую направленность географического образования, которая выражается в особом внимании к формированию специфических для географии умений и навыков в тесном единстве с системами изучаемых теоретических и эмпирических знаний, раскрытию прикладного, конструктивного характера современной географической науки, что определяет разработку методических рекомендаций и системы практических заданий для учащихся разных типов учебных заведений в качестве приложения к атласам разного уровня.

Исходя из сформулированных методических принципов была разработана структура учебнокраеведческого электронного атласа Саратовской области.

Структура электронного атласа как картографического произведения должна быть достаточно четко определена. Главные структурные вопросы для любого атласа заключаются в последовательности размещения тематических карт и в каждом разделе [1].

Содержание картографического блока «учебно-краеведческого электронного атласа Саратовской области», развертывается в следующих крупных тематических разделах и подразделах, обеспечивающих полноту охвата картами и другими материалами ключевой проблематики региона.

Первый раздел атласа - вводный, сюда входят карта географического положения Саратовской области на карте России, административная и физическая карты Саратовской области.

Далее следует раздел карт природы. Разнообразие карт природы определяется многочисленностью их сюжетов. Последовательность размещения в атласе карт природы обычно соответствует характеру и выраженности основных природных связей. В разрабатываемом атласе к этому разделу отнесены следующие карты: геологическая, климатическая, гидрологическая, почвенная, растительности, зоогеографическая и ландшафтная.

Следующий социиально-экономический раздел атласа посвящен населению, его социальнодемографическим характеристикам и характеристикам хозяйства области, за ними следуют карты инфраструктуры. 
Затем следует раздел эколого-географических карт. Это связано с возрастающей ролью экологического воспитания. Практически в каждой теме рассматриваются вопросы охраны окружающей среды. Включение этих карт позволит наглядно отразить экологические проблемы, их масштаб и территориальную приуроченность.

Самостоятельный раздел образуют исторические карты: истории заселения области, истории освоения территории области и др. [2].

Кроме картографического блока атлас включает еще несколько функциональных блоков: текстовой (научно-справочный), космо-, фото- и видеоизображений, практических работ, тестирования, блок моделей.

В справочной системе атласа даются разъяснения по структуре атласа и общему его использованию.

Текстовый блок мультимедийного атласа включает справочную информацию по территории Саратовской области. Текстовая информация, так же как и картографическая, представлена для удобства пользователей в виде справочной вкладки с аналогичными разделами: «Вводный», «Природа Саратовской области», «Население и хозяйство Саратовской области», «Экологическое состояние Саратовской области», «История Саратовской области». В статьях этих разделов будут содержаться имеющиеся в настоящее время сведения по рельефу, климату, внутренним водам, ландшафтам, растительному и животному миру, охраняемым территориям, памятникам природы, истории освоения края, об административно-территориальном делении, населении (численность, национальный состав, религии и др.), экономике и населенных пунктах области.

Основой для создания этих разделов может послужить опубликованное школьное пособие «География Саратовской области» [3]. При использовании новых статистических данных, а также схем и иллюстраций учащиеся смогут получить более полную картину по той или иной теме.

Кроме этого, в атласе планируется представить блок мелкомасштабных и крупномасштабных космических изображений, их можно будет сопоставить с различными картами атласа.

Предполагается блок практических работ, в котором должна быть осуществлена возможность интерактивной работы с тематическими, в частности экономико-географическими, картами атласа (построение карт по табличным данным, которые можно обновлять). В этот блок также будет включена работа с контурными картами, а также представлена возможность их вывода на принтере в разной степени генерализации (для выполнения «вручную» различных заданий).

Блок тестирования позволит преподавателю проверить уровень усвоения пройденного на уроке, а школьнику - осуществить самоконтроль в процессе подготовки к занятиям.
Блок моделей даст возможность увидеть «с птичьего полета» ландшафт современного города, а также посмотреть трехмерную модель основных достопримечательностей Саратовской области, таких как Кумысная поляна или Хвалынский национальный парк.

Технологически реализация данной структуры в рамках разработки атласа должна опираться на следующие этапы работы.

I этап. Постановка задания. Формирование требований к проекту. Составление технического задания по разработке электронного атласа. Написание развернутой программы атласа.

II этап. Выбор формальной структуры электронного атласа, моделей баз данных, объектов и потоков информации. Разработка сценария и синтез модели. При создании сценария необходимо предусмотреть последовательность работы с атласом, возможность изменения хода работы и выхода из него (завершение работы).

III этап. Форма представления информации и выбор программных продуктов.

После разработки сценария и создания модели определяются программные продукты для реализации проекта. На этом этапе необходимо использовать два вида программных продуктов:

- для подготовки и обработки материалов, составляющих проект (геоинформационных данных, графических объектов, аудио- и видеозаписей, текста);

- для создания электронного атласа, разработки пользовательского интерфейса атласа.

После выбора программных средств определяются форма представления информации и инструменты для ее реализации.

IV этап. Синтез компьютерной модели объекта.

После анализа возможностей выбранных программных продуктов электронный атлас реализуется на компьютере. В процессе этого предстоит пройти следующие две стадии.

1) подготавливается картографический, текстовый, гипертекстовый (документ, содержащий ссылки на другие документы), аудио- и видеоматериал при помощи выбранных программных продуктов. Этот этап требует определенных навыков и знаний различных программных продуктов.

2) создается и тестируется компьютерная модель.

V этап. Работа с электронным атласом.

На этом этапе проектирования и разработки атласа осуществляется предварительное тестирование атласа - функциональное и структурное. Происходит проверка соответствия поведения программы ее внешней спецификации. При структурном тестировании осуществляют проверку логики содержания и работы атласа.

На первых этапах в рамках разработки программы атласа были обозначены основные положения: тип атласа по содержанию, круг потребителей, основные задачи, на решение которых рассчитан атлас. 
Атлас как система карт имеет свою уникальную структуру, которая подразумевает особую «жесткость» построения. В атласной картографии она определяется следующими главными факторами $[1,4]$ :

- картографируемым пространством, его размерами и географическими особенностями;

- назначением, т.е. кругом основных пользователей и техническими условиями работы с атласами;

- содержанием - широтой и глубиной информации, заложенной в атласе, пределами освещения того или иного природного и социальноэкономического явления или их совокупности.

По своей структуре и содержанию учебнокраеведческий электронный атлас Саратовской области относится к «общим комплексным атласам». Они представляют собой наиболее сложные по построению атласы, дающие разностороннюю характеристику территории, отражающие явления в их взаимосвязи и зависимостях.

Электронный атлас Саратовской области носит учебно-краеведческий характер. Он ориентирован на научное и учебное применение. Атлас опирается на подробные современные достоверные и точные знания и материалы.

Создание такого атласа направлено на обобщение современной информации о Саратовской области (природе, ресурсах, населении, хозяйстве, экологии, истории, наследии, а также предпосылках и перспективах устойчивого развития).

На третьем этапе решалась задача определения программных средств реализации электронного атласа, поскольку это один из наиболее важных моментов, наряду с традиционными для картографии вопросами разработки его структуры, содержания, компоновки, способов изображения и т.п.

При выборе программного обеспечения для реализации поставленных задач учитывались следующие требования:

- возможность быстрого ввода и редактирования графической и табличной информации;

- наличие аппарата, позволяющего производить логико-математическую обработку и трансформацию изображения (оверлейные операции, проекционные преобразования и т.д.);

- наличие блока обмена данными с другими программами-системами (экспорт/импорт).

Создание электронного атласа основывается на методах и методиках построения мультимедийных произведений и геоинформационном картографировании.

Техническое обеспечение создания атласа будут обеспечивать программные продукты различного направления:

1) геоинформационные программные продукты для подготовки картографического материала и экспортирования его в мультимедийную среду: MapInfo Professional компании MapInfo Corporation, ArcGis компании ESRI и др.;
2) мультимедийные программные продукты для преобразования материала и создания мультимедийного атласа: Macromedia Flash, Macromedia Fireworks, Macromedia Director компании Adobe;

3) графические редакторы для обработки фотографического и других материалов (Adobe Photoshop компании Adobe) и составления карт (CorelDraw компании Corel Corporation);

4) сетевые и серверные программные продукты для публикации атласа и интерактивных модулей в сети Интернет и работы с серверами: Macromedia Homesite, Macromedia Dreamweaver компании Adobe, Apache HTTP Server компании Apache Software.

В качестве основного программного продукта на этапе подготовки картографических баз данных была выбрана система настольной картографии MapInfo Professional. Это полнофункциональная векторная ГИС, имеющая возможность работать с табличными базами данных, позволяющая реализовать все функциональное этапы геоинформационного картографирования - от ввода данных до оформления итогового отчета и вывода готовой продукции.

На всех этапах работы по созданию атласа особое внимание уделялось следующим аспектам: возможностям и методам использования атласа, разработке структуры разделов, выбору картографической основы, определению требований к программному обеспечению, методическим вопросам подготовки цифровой основы. Оценка перечисленных параметров позволила разработать методику составления электронного атласа и наметить комплекс мероприятий по сбору и обработке необходимой информации, определить ее объем и характеристики.

Основными требованиями при выборе исходной картографической основы являлись:

- точность изображения (изображение хорошо читаемо, выполнено на слабо деформирующемся материале);

- современность;

- соответствие требованиям руководящих нормативных документов.

В соответствии с перечисленными параметрами в качестве географической основы была использована актуализированная топографическая карта Саратовской области (на 6 листах) масштаба 1 : 2000001996 г. издания, оцифрованная в лаборатории геоинформатики и тематического картографирования географического факультета СГУ.

Для создания карт природы использовались ранее опубликованные источники. Для составления карт социально-экономического и демографического разделов применялись данные, опубликованные территориальным органом федеральной службы государственной статистики по состоянию на 1 января 2008 г. и 1 января 2009 г.

При разработке структуры и содержания географических атласов Саратовской области для разных целевых категорий учитывался также 
опыт создания двух обычных атласов: Атласа Саратовской области и Эколого-ресурсного атласа Саратовской области (комплект настенных карт).

Атлас Саратовской области 1978 г. является на данный момент наилучшим комплексным картографическим произведением, разработанным для нашей области. Основа его содержания - тематические карты масштаба $1: 2250$ 000. Он включает в себя административную карту, физическую, геологическую, тектоническую, карту четвертичных отложений, серию климатических и фенологических карт, почвенную карту, карту растительности, зоогеографическую карту, карту охраны природы, серию экономических карт (их информация устарела, так как атлас выходил в 1978 г.), которые можно использовать при изучении географии Саратовской области.

Эколого-ресурсный атлас Саратовской области под редакцией В.С. Белова 1995 г. - одно из последних картографических произведений по нашей области. Он включает 11 карт по данной тематике масштаба $1: 500000$.

В процессе векторизации был сформирован набор базовых графических слоев, которые содержат границы административнотерриториального деления территории, гидрографическую сеть, железные и автомобильные дороги, населенные пункты и др. Каждый объект слоя описан набором показателей. Например, все объекты слоя «Населенные пункты» охарактеризованы по следующему шаблону: код объекта, его название, статус населенного пункта, количество населения и т.д.

При создании электронного атласа необходимо учесть особенности способа его воспроизведения на мониторе компьютера или через проектор, а также необходимо выбрать модель представления данных, которая должна отвечать следующим требованиям:

- наглядности представления информации;

- простоте ввода и получения информации;

- удобству поиска, просмотра и отбора информации;

- возможности использования информации из других программных продуктов;

- возможности оперативного обновления атласа;

- обладать дружественным интерфейсом, обеспечивающим интерактивный режим.

Материалы, содержащиеся в тематических разделах, представлены внутри электронного атласа в различных форматах. Точность карт в атласе (и их производных - на бумаге), размеры условных знаков (в частности, толщины линий) должны соответствовать требованиям действующих в настоящее время инструкций по составлению карт соответствующих масштабов, а также стандарта на цифровые карты.

Как при разработке карт для бумажной версии, так и для карт, входящих в электронный атлас, особое внимание должно уделяться качеству картографических изображений: соответствию предписанным допускам и нормам составления карт, полноте, географической, топологической и текстовой корректности, точности, загруженности, качеству графики, читаемости и выразительности.

Очень важным условием исполнения данного программного продукта должно быть применение такого программного обеспечения, которое будет позволять работать с электронным атласом на любых компьютерах - с любыми процессорами, любой операционной системой и любым объемом оперативной памяти. Обязательное условие - наличие дисковода для прочтения компакт-дисков или связь с Интернетом при работе с сетевой версией атласа.

Электронный атлас должен представлять собой вполне законченный информационнотехнологический продукт, обеспечивающий широкие возможности по накоплению, визуализации, обновлению, анализу и моделированию пространственно-определенной информации в прикладных и познавательных целях.

Для более эффективного использования издание должно быть снабжено алфавитным указателем, а также списком сокращений.

\section{Заключение}

Электронный атлас - прямой наследник классических бумажных атласов, созданный с использованием современных компьютерных технологий. Атлас, являясь системным собранием взаимосвязанных и взаимодополняющих друг друга карт, разрабатывается по единой программе как целостное произведение и издается в виде книги или комплекта листов [5]. Электронный атлас представляет собой фактически программный продукт, распространяемый на любых носителях электронной информации и по каналам Интернета. Как и в классическом понимании, электронный атлас является географической энциклопедией, в которой концентрируется знания и представления о местности и жизни общества. Информация передается в нем в наглядной, доходчивой для прочтения, изучения и использования форме.

Основные задачи электронного регионального атласа заключаются в том, чтобы:

- дать свод современных информации и знаний о регионе - природе, ресурсах, населении, хозяйстве, экологии, истории, наследии, а также предпосылках и перспективах устойчивого развития;

- предоставить пользователю достоверный материал для формирования федеральных и региональных научно-технических и иных проектов, программ и инициатив экономического, экологического, культурно-исторического, геополитического, геостратегического и иного значения; 
- дать импульс повышению интереса к региону и его изучению.

Атлас как автономный и сетевой продукт может служить каналом связи между различными целевыми группами пользователей атласа.

Учебно-краеведческий электронный атлас Саратовской области - произведение нового поколения, воплощающее в себе современные технологии и большой массив географических знаний, сохраняющее преемственность с известными образцами отечественной картографической продукции. Как целостное произведение атлас может стать информационно-справочной системой, содержащей различную информацию о регионе, которая благодаря сети Интернет может быть доступна большому числу пользователей.

\section{Библиографический список}

1. Сваткова Т.Г. Атласная картография. М., 2002. 203 с.

2. Паршина Ю.В. Структура и содержание учебного электронного географического атласа Саратовской области // ИнтерКарто/ИнтерГИС 14: Устойчивое развитие территорий: теория ГИС и практический опыт: Материалы Междунар. конф., Саратов, Урумчи - 2008. Саратов, 2008. C. 262-265.

3. Демин А.М., Макариева Л.В., Уставщикова С.В. География Саратовской области. Саратов, 2008. 336 с.

4. Берлянт А.М., Востокова А.В., Кравиова В.И. и др. Картоведение. М., 2003. 477 с.

5. Берлянт A.M. Картография: Учебник для вузов. M., 2002. $336 \mathrm{c}$.

УДК [581.526.53:630*182.4] (470.44)

\section{ДРЕВЕСНО-КУСТАРНИКОВАЯ РАСТИТЕЛЬНОСТЬ КАК ЭЛЕМЕНТ ЛАНДШАФТОВ ПОЛУПУСТЫННОГО САРАТОВСКОГО ПРИУЗЕНЬЯ}

\section{Н.В. Пичугина}

Саратовский государственный университет, кафедра физической географии и ландшафтной экологии E-mail: geogr@sgu.ru

Статья посвящена анализу места древесно-кустарниковой растительности природного и антропогенного происхождения в структуре и функционировании ландшафтов полупустынного Саратовского Приузенья. В работе использованы материалы полевых исследований разных лет, топографические и тематические карты, космические снимки, элементы ГИС-технологий.

Ключевые слова: ландшафты, полупустыня, Саратовская область, Заволжье, древесно-кустарниковая растительность.

Tree-shrubbery Vegetation as the Element of Landscapes of semi-desert Saratov Priuzenye

\section{N.V. Pichugina}

This article is devoted to the analyses of the role of tree-shrubbery vegetation of natural and anthropogene origin in the structure and functioning of landscapes of semi-desert Saratov Priuzenye. In this work there are used the materials of field field researches of different years, topographic and subject charts, space photographs, elements of GIS-technologies.

Key words: landscapes, semi-desert, Saratov Region, Zavolzhye, tree-shrubbery vegetation.

Ассоциативно северная полупустыня Прикаспийской низменности воспринимается как плоская безлесная равнина с однообразным внешним обликом. Вместе с тем более близкое знакомство с исследуемой территорией открывает интересные и эффектные элементы ее ландшафтной структуры, одним из которых является древеснокустарниковая растительность.

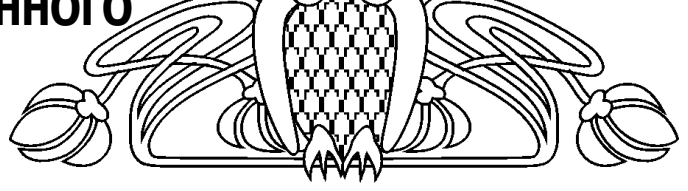

Целью представленной работы являются рассмотрение состава древесно-кустарниковой растительности природного и антропогенного происхождения, анализ ее роли в функционировании геосистем. Для исследования выбрана территория полупустынного Саратовского Приузенья.

Исходные материалы и источники. В рамках данной работы были использованы: материалы полевых исследований 1990, 1992, 1997 , 1998, 2004, 2007 и 2009 гг., топографические и тематические (почвенные, ландшафтные и др.) карты, космические снимки, научные публикации (монографии, статьи).

Методы исследования: описательный, сравнительный, картографический с использованием геоинформационных технологий. Для определения местоположения в полевых условиях применялся GPS-приемник.

Исследуемая территория административно охватывает юго-западную часть Новоузенского района (около 25\% от площади района) и $97 \%$ Александрово-Гайского района Саратовской области.

Со второй половины XX в. к вопросу физикогеографического районирования Саратовского Заволжья обращались многие исследователи: П.С. Кузнецов [1], Н.К. Алексеевская и М.А. Шабанов [2], А.К. Пестряков и др. [3, 4], А.Г. Доскач [5], И.В. Копыл [6] и В.А. Николаев [6, 7], В.3. Макаров и др. [8, 9], Н.В. Пичугина [10] и др.

Неизменным на схемах ландшафтного районирования было выделение на крайнем юге левобережья Саратовской области полупустынной зоны. В пределах Волго-Уральского междуречья 